\title{
Devices for the pre-dilution of sewage at submerged outfalls
}

\author{
A. R. AGG \& W.'R. WHITE
}

\section{Mr Agg}

The design of a sea outfall for the disposal of sewage or trade wastes involves measures to ensure rapid dilution of the effluent with sea water under a wide range of prevailing conditions. Once the effluent is in the sea it will be dispersed by forces which the engineer can measure, but over which he has no control. However, the arrangement of the discharge ports does provide him with considerable flexibility in choosing a design which will achieve a predictable degree of dilution immediately over the outfall.

49. A high degree of initial dilution has several advantages. These include a proportionately greater dilution at points remote from the outfall, the encouragement of vertical mixing due to the smaller density discontinuity between the effluent field and the sea water, less tendency for visible surface slicks to be formed and a more rapid reduction in the concentration of any toxic constituents of the effluent.

50. Initial dilution is determined, among other parameters, by the depth of water, so that to achieve a certain level of dilution at a particular coastal site may mean an unduly long outfall pipe. Thus the possibility of achieving additional dilution by inducing pre-dilution within the outfall itself before the mixed effluent is discharged was investigated in a series of feasibility experiments.

\section{Dr White}

The uses of pre-dilution devices can be considered under two headings. First, the devices could be used for improving the performance of existing outfalls and second they might be considered for a new installation at the design stage. In the former case the aim would be to alleviate pollution problems by making a relatively simple modification to an existing sea outfall, and in the latter situation the aim would be to achieve the required initial surface dilution levels for the minimum cost. By using a pre-dilution device the required initial surface dilution could be achieved in a shallower depth of water and, depending on the offshore slope of the beach, a significant reduction in pipe length is possible.

52. The pre-dilution devices have been shown to produce dilution factors between 5 and 15 within the device, but the advantage is less marked when the effluent jet reaches the surface. Comparing initial surface dilutions with and without a predilution device conditions are improved typically by a factor of about 2 .

Paper published: Proc. Instn Civ. Engrs, Part 2, 1974, 57, Mar., 1-20. 
Mr J. D. C. Osorio, Lewis \& Duvivier

It seems that after five years outfalls with multiple diffusers are not behaving as they did when first installed. What is the safe Froude number or jet velocity? The Authors point out that maximum dilution occurs normally at a low Froude number, probably at one, or one is trying to design down to the lowest possible flux velocity. The Paper seems to indicate that at a Froude number of one there is entrainment of sea water in the outlet. I envisage this in the following way. As the port operates as an inverted weir, so effluent flows out of the top of the port and sea water comes into the bottom. So unless the Froude number remains at unity when this occurs there are various possibilities.

54. If there is a multiport system, the discharge will not occur stably between the various ports, because of differences of tidal current, differences in level between ports and so on. The chances are that more plume will come out of some ports than others, and it is impossible to know what will occur.

55. Parts of the system during periods of low plume may remain in sea water rather than sewage for a long time, which will result in marine fouling. Barnacles grow, followed by mussels.

56. Incoming sea water will inevitably carry some sediment which is likely to settle in the outfall. Therefore $I$ feel it is unwise to use Froude numbers of less than about three for average dry weather flow. The device recommended by the Authors seems to offer a possible way out of this. The velocity can be kept up throughout the pipe system unless it is on the sea bed, where it does not matter if there is sedimentation. However, there is always a possibility that fouling and sedimentation within it will upset the performance demonstrated on the model scale. I shall be interested to see the first installation. I cannot imagine how such a device can be installed without upsetting the fishing fraternity and remaining vulnerable to damage by anchors.

57. I am confused about the Authors' statement that the better mixing was achieved at the highest ambient velocity. That does not seem to agree with Table 2.

Mr F. E. Bruce, Imperial College of Science and Technology

I am puzzled by the fact that the relationship between initial dilution and the depth/ diameter ratio shown in the new charts is exactly the reverse of that given by Abraham's curves. Could the Authors' show their chart for zero ambient velocity? The reference to 'increasing values of $D / y^{\prime}$ ' in $\S 7$ is a little misleading because an increase

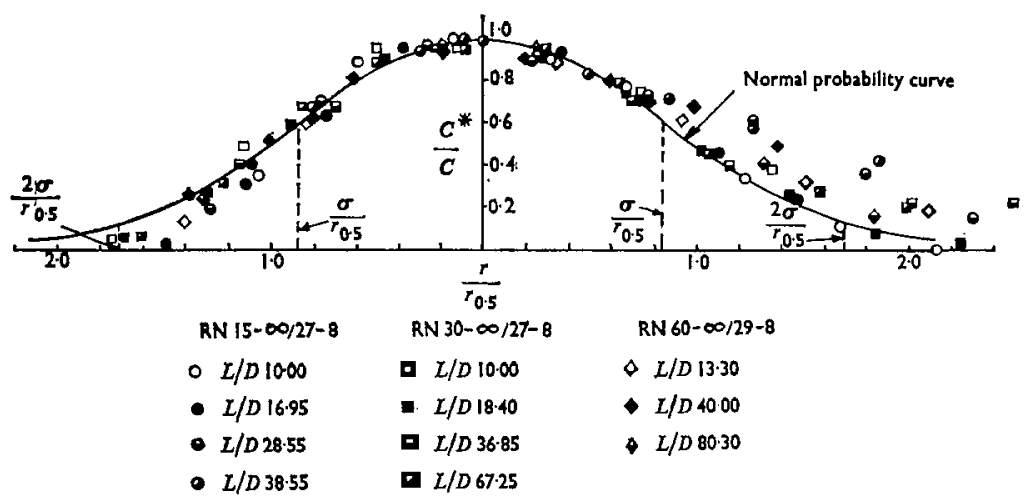

Fig. 16. Normalized concentration distribution (still ambient) 


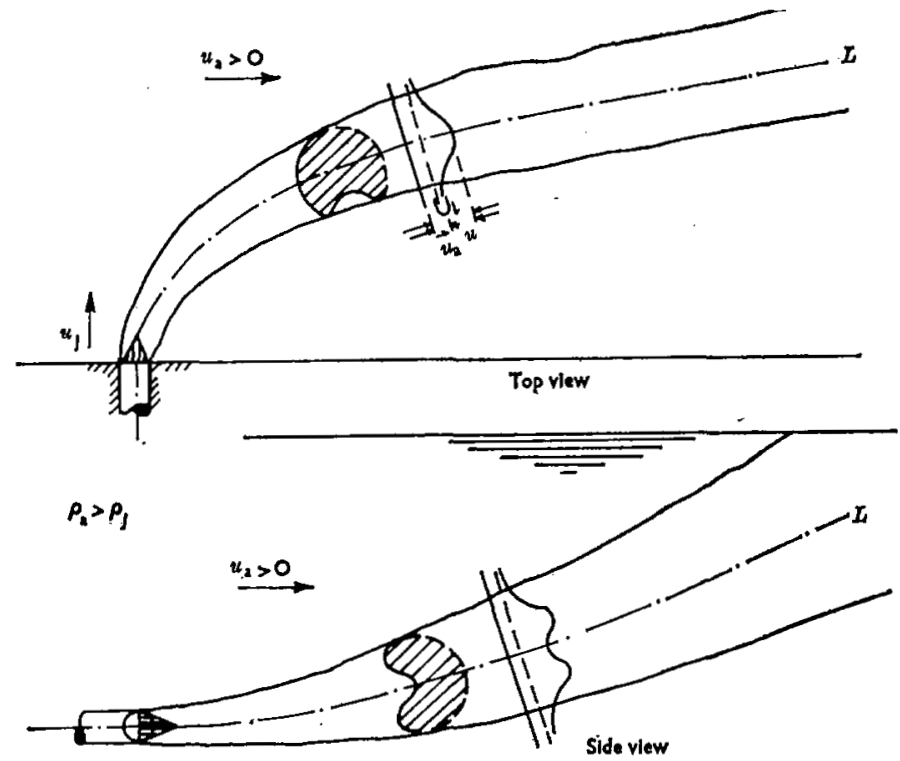

Fig. 17. Buoyant jet discharged horizontally into a moving ambient fluid (cross flow)

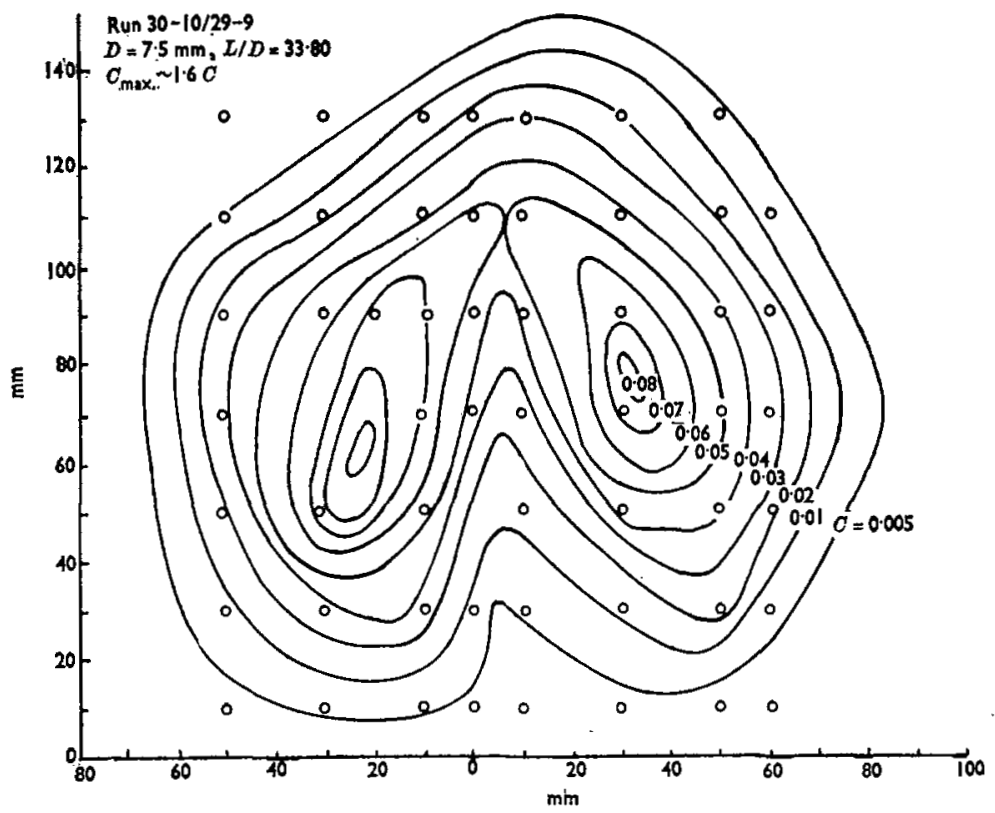

Fig. 18. Complete concentration profiles (cross flow) 
in this ratio could be achieved by decreasing $y$ instead of increasing $D$. This would lead to the absurd result that there would be better initial dilution if the discharge were at the surface. Could the Authors explain this apparent fallacy, which seems to arise from attaching too much significance to a dimensionless ratio?

59. No mention is made in the Paper of the direction of the ambient current in relation to the direction of the sewage discharge. With some of the devices used by the Authors this does not matter, but with a simple jet the relative direction makes a distinct difference to the dilution achieved. Fig. 16 shows the typically normal distribution of the sewage concentration along a diameter of a jet discharged into still water. The measurements shown were obtained by Ayoub ${ }^{8,9}$ in laboratory scale experiments at Imperial College of Science and Technology. Fig. 17 shows the effect of discharging the jet at right angles to the ambient current. The jet is split into two vortices so that a cross-section shows concentration contours as in Fig. 18. The overall effect is that, at a given distance along the trajectory, the dilution of a jet in a cross-flowing current is about twice that of a jet flowing with the current. This is about the same advantage as is given by the best of the Authors' devices. It might be simpler, therefore, merely to ensure that a discharge of sewage in the sea is directed at right angles to the general direction of the tidal currents.

60. How do the Authors calculate the dilution at the surface after the original jet has been converted to a different configuration when it emerges from a dilution device?

\section{Mr J. Finch, President, Institute of Water Pollution Control}

I feel that one of the key words in the Paper is 'density'. Differences in sewage density and sewage treatment can cause various troubles. There is a problem with settling tanks caused by sewages of different densities, and particularly the sewages in areas where there are large proportions of industrial effluent. I wonder whether density has been taken sufficiently into account. It seems that much of this investigation may have been done on certain density parameters. If this is so, what were the parameters? There may be a case where certain equipment designed in terms of a certain density may work well at one particular density, and not at another. For sewage with industrial effluent which may have a density less than the sewage, different types of sewage might be diluted in different ways as a result of density.

62. I have studied the number and types of device which have been used. Presumably simple devices such as the simple grid systems have been tried out. In some work dealing with dilution problems which was carried out with grid systems the results were extremely good. The flow of liquid past the diffuser jets was such that the end of the pipes became polished, indicating that there was a great deal of water passing.

63. In $\S 18$ the words 'sewage' and 'effluent' have both been used; I assume that when the Authors refer to 'effluent' in the third line, they are still speaking of sewage.

\section{Mr J. Lovatt, Howard Humphreys and Sons}

I have been concerned in recent years with effluent discharges into the Mediterranean Sea where there is the problem of practically no tide. I think the Authors' work is a valuable contribution to solving some of the problems associated with sea outfalls, particularly where there are tidal problems. In North Africa where the tidal variation is very small, it would have been simpler and much cheaper if it had been possible to discharge sewage, partially treated, into the sea. However, this was impracticable because of the tidal problems along the coast. On the south coast of France there is a pressing need for something to be done about sewage treatment but there is little land available on the Riviera for building sewage treatment plants and sea outfalls would have obvious advantages. Have the Authors any comments on this problem so far as the Mediterranean is concerned? The problem is made more complicated by high temperatures and the possible danger to the coastal amenities. 

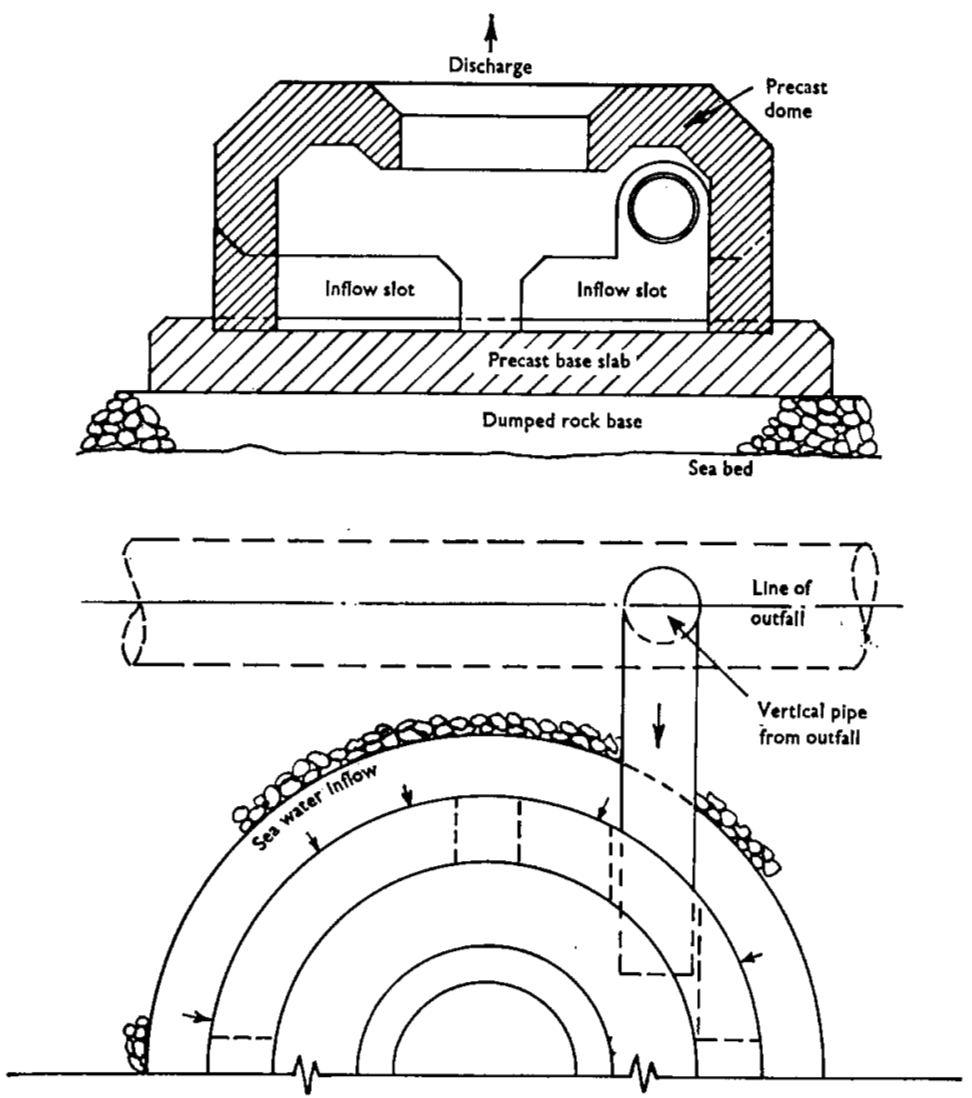

Fig. 19. Possible method of construction of type $\mathrm{J}$ outlet

Mr P. Ackers, Binnie and Partners

I have considered how the results of the Authors' work would be used in practice, and envisage their type $J$ outlet being constructed as shown in Fig. 19.

66. A layer of broken rock would be dumped at one of the outfall sites and trimmed to a level surface. On this would be placed a precast concrete base in the form of a disc with a rim at the edge. The dome itself would also be precast concrete and the slot around its perimeter would be formed by its four stub legs. At one point there would be a groove through which the branch pipe from the outfall itself would gain access to the upper part of the dome. The example considered was for a pumped outfall with a maximum discharge of about $0.04 \mathrm{~m}^{3} / \mathrm{s}$ at each diffuser outlet. The base diameter of a type $J$ outlet would be about $4.5 \mathrm{~m}$ and the overall height above sea bed about $3 \mathrm{~m}$. The discharge opening at the top would be $1.5 \mathrm{~m}$ in diameter and the outfall branch $0.5 \mathrm{~m}$ in diameter. It was assumed that the line of the outfall would be about $4 \mathrm{~m}$ from the centre of the type $J$ outlet domes.

67. Could the Authors comment on this practical interpretation of their proposals? There may be problems with anchors, fouling by marine growths, settle- 
ment of sediments and so on, and it would be interesting to know if field scale trials were planned to support the model results and examine practical aspects of design.

68. The advantage to be gained by using a pre-dilution system might be crucial in gaining acceptance for submarine outfalls in holiday areas where water skiers, bathers and divers make full use of the sea. In this connexion, schemes designed to carry, say, six times the dry weather flow via a pumping station at the shore might include provision for admitting sea water into the pumping station sump during dry summer conditions to add to the overall dilution factor. Comparative figures of surface dilution for a particular case were based on the pre-dilution results in the Paper, with the information on dilution in the plume with and without currents.

69. The comparison in Table 5 of predicted performance in a particular case becomes significant in relation to limiting surface dilution figures of 1 in 50,1 in 100 and 1 in 400 for inhibited vertical mixing, slick formation and visual detection respectively. This is especially so as the cost of extending an outfall to deeper water would be far greater than the cost of providing pre-dilution devices at the diffusers. Could the Authors explain more fully their demand curve in assessing the acceptable initial dilution? The lack of any generally agreed figure may be leading to greater expenditure on very long sea outfalls than could really be justified on health, amenity or environmental grounds.

70. The model tests were carried out using heated water to provide the buoyant discharge, but in reality buoyancy comes mostly from the difference in salinity between sewage and sea water. Is it possible that heat conduction through the metal models may have reduced the temperatures measured at the outlet, and so given too high a figure for pre-dilution? Do the Authors consider further laboratory work to be necessary before using these devices in actual projects?

\section{Professor J. R. D. Francis, Imperial College of Science and Technology}

Are the Authors sure that the absolute size of their experiment has not affected the concentrations that they measured? Device $J$ reminds me of the swirl atomizer; swirl atomizers invariably work best when they are small, and this is because they produce a thin sheet of fluid which is eaten away by boundary layers on each side. Boundary layers are not respectors of scale: their form depends on certain parameters that are not proportional to the size of the solid boundaries; thus reducing the size of a device which depends on boundary layers causes the layers to occupy more of the fluid space. Mixing takes place in the layers, so it therefore seems that these rather

\section{Table 5}

\begin{tabular}{l|c|c|c}
\hline & At sea bed & \multicolumn{2}{|c}{ At surface } \\
\cline { 2 - 4 } & $\begin{array}{c}\text { No ambient } \\
\text { current }\end{array}$ & $\begin{array}{c}\text { With } \\
\text { current }\end{array}$ \\
\hline $\begin{array}{c}\text { Twelve 0.15 m pipe outlets discharging 6 dwf } \\
\text { sewage intermittently }\end{array}$ & 1 & 120 & $120^{*}$ \\
$\begin{array}{c}\text { Twelve type J mixers discharging 6 dwf } \\
\text { sewage intermittently }\end{array}$ & 10 & $85 \dagger$ & 270 \\
$\begin{array}{c}\text { Twelve 0.15 m pipe outlets discharging 2 dwf } \\
\text { sewage plus 4 dwf sea water } \\
\text { Twelve type J mixers discharging 6 dwf } \\
\text { sewage intermittently }\end{array}$ & 3 & 340 & $340^{*}$ \\
\hline
\end{tabular}

- No additional dilution because of low ratio of ambient current to outlet velocity. $\uparrow$ Poorer overall performance in still water because of low outfall Froude number. 
small experimental devices, which are perhaps only 1-2 inches in diameter, will give good dilutions and good drops in the concentration, compared with large precast concrete devices to be used in a prototype. Unless there is evidence to the contrary, I should have thought that large-scale field tests might give disappointing dilution factors compared with the small-scale experimental devices.

\section{Mr J. de B. Ashworth, John Taylor and Sons}

How true are the comparisons in the factors for moving water dilution? In the diffuser system high velocity comes from the diffuser, perhaps mixing with the low ambient velocity. This gives a small ambient velocity over diffuser velocity, possibly giving very high dilution factors.

73. Coliform kill seems to have a basic relationship with pollution. Do the Authors think the coliform kill should not be considered as an active factor?

74. For sea outfalls ratios of 50,100 and 400 for various forms of slick have been given. Are these values directly related to the multiport diffuser system? They seem high.

\section{Mr C. S. Lindsay, Glasgow}

No work that I have seen has extended the initial dilution calculations and discharges into the full concept of mass transfer of water to find out the build-up in the area.

76. Could the Authors give the figures which would compare the multiport outfall with the outfall figures they have used in $\S 43$ ?

77. As a designer I found difficulty in envisaging how I would ask a contractor to develop some of these complex devices.

78. In $\S 45$ the Authors state that model D was excessively large in relation to the diameter of the jet and the rate of effluent flow. Would the Authors amplify this?

79. In Scotland designs have been developed using the hydraulic analysis. What effect does the solids content have on this?

Mr J. T. Calvert, John Taylor \& Sons

I think there is no doubt that in the disposal of sewage to sea there are two predominant factors. First, there is the removal of visible solids, because most complaints arise from visible solids being deposited on beaches. The second factor is one of dilution. With a crude sewage and a dilution of 1 in 100, the liquid is in effect indistinguishable from a fully purified effluent. It has lower suspended solids, lower biochemical oxygen demand and probably a lower coliform count. Therefore the Water Pollution Research Laboratory has investigated every possible method of increasing the dilution when the sewage is discharged out to sea.

81. If the length of the outfall can be halved by having a relatively cheap device fitted to it, then a satisfactory disposal method can be achieved and also a great deal of money can be saved.

\section{Mr H. R. Oakley, J. D. and D. M. Watson}

Practical engineers will take heart on learning from the Authors that their preferred model did not behave in the expected mode.

83. The importance of ambient flow is difficult to overemphasize but, having in mind the distribution of flow in the vertical plane, definition of the term is essential. Would the Authors say what definition is used in the Paper? Is it the same as that used by Agg and Wakeford ${ }^{1}$ ?

\section{Dr J. J. Sharp, Faculty of Engineering. Memorial University of Newfoundland}

In attempting to achieve a convenient, partial, solution to a practical problem it is important to ensure that variables of interest-in this case design variables as opposed 


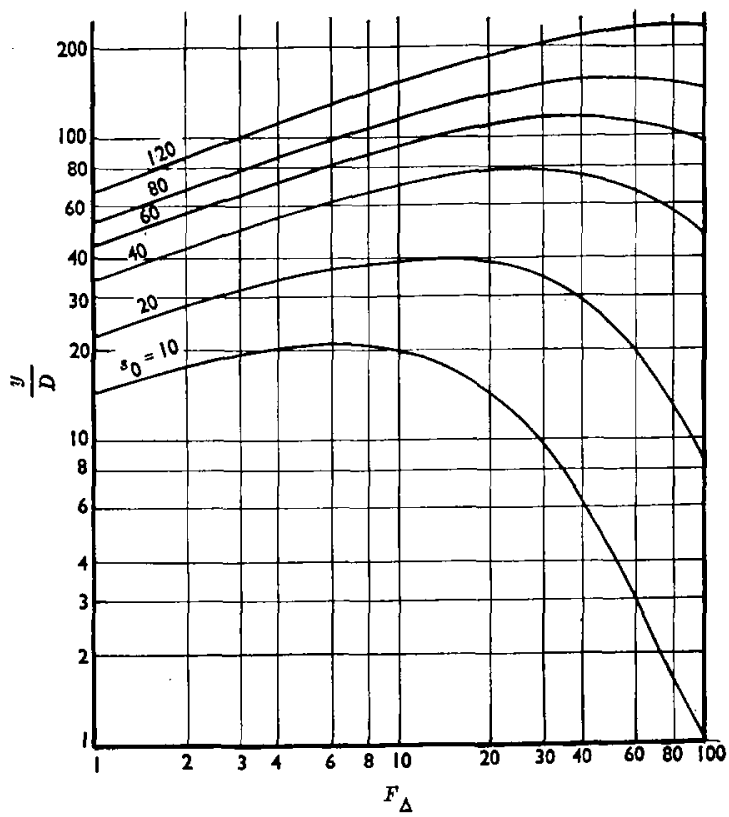

Fig. 20. Abraham's solution ${ }^{2}$ for dilution

to variables pertaining to site conditions-appear as infrequently as possible in the solution. In equation (4) the Authors have achieved this essentially by using depth and net acceleration as the repeating variables. Thus charts produced on the basis of the groups which appear in this equation will provide direct information, not only on how variation in diameter affects dilution for prescribed flow and site conditions but also on how variation in ambient velocity and flow affect the dilution for a chosen diameter.

85. Alternative equations could be developed to show the effects of varying depth, ambient velocity and diameter but not discharge, e.g.

$$
\frac{C_{0}}{C_{\mathrm{m}}}=\phi\left[\frac{Q^{2 / 5}}{\left(g^{\prime}\right)^{1 / 5} D}, \frac{Q^{2 / 5}}{\left(g^{\prime}\right)^{1 / 5} y}, \frac{u_{\mathrm{a}}{ }^{2}}{Q^{2 / 5}\left(g^{\prime}\right)^{4 / 5}}\right] \quad . \quad . \quad . \quad . \quad .
$$

where $g^{\prime}=g\left[\left(\rho_{\mathrm{a}}-\rho_{0}^{\prime}\right) / \rho_{0}\right]$, or to show the effects of varying diameter, depth and discharge but not ambient velocity, e.g.

$$
\frac{C_{0}}{C_{\mathrm{m}}}=\phi\left[\frac{u_{\mathrm{a}}{ }^{2}}{Q^{2 / 5}\left(g^{\prime}\right)^{4 / 5}}, \frac{u_{\mathrm{a}}^{2}}{g^{\prime} y}, \frac{u_{\mathrm{a}}{ }^{2}}{g^{\prime} D}\right]
$$

86. As each of the repeating variables used to generate equations (4)-(6) (i.e. $y, Q$ and $u_{\mathrm{a}}$ ) is likely to vary at any particular site it is probable that none of these equations is significantly better than any other. However, because of the relatively large variation which might be expected in depth and discharge compared with ambient velocity it is considered that equation (6) might be marginally better than the others. This argument does not take into account the shape of the various design diagrams and this could outweigh the argument because some diagrams could be more sensitive to error than others. 
87. It is believed that the interpretation of the charts in Figs 1-3 is not as simple as is stated in $\S 7$. Data shown in these charts range essentially from values of $D / y=10^{-2}$ at $Q / y^{5 / 2}\left(g^{\prime}\right)^{1 / 2}=10^{-5}$ to $D / y=10^{-1}$ at $Q / y^{5 / 2}\left(g^{\prime}\right)^{1 / 2}=10^{-2}$. This range, presented in a more traditional form, is from $F r \simeq 1 \cdot 3$ at relative depth $y / D=100$ to $F r \simeq 4.0$ at $y / D=10$. Fig. 20 reproduces Abraham's ${ }^{2}$ solution for dilution and it is apparent that the Authors' charts are restricted to an area of Fig. 20 in which reduction in $F r$ at constant $y / D$ increases dilution. In the other part of Fig. 20 (large $y / D$, large $F r)$ the opposite is true.

88. For example if $y / D=40$ and $F r=60$ then from Fig. $20 C_{0} / C_{m} \simeq 30$. If $D$ is doubled and all other variables are kept constant $y / D=20, F r=10.6$ and from Fig. 20 $C_{0} / C_{\mathrm{m}} \simeq 15$, i.e. the dilution is halved. This trend is also apparent at lower Froude numbers, e.g. for $y / D=80$ and $F r=10, C_{0} / C_{\mathrm{m}} \simeq 50$. Again by doubling $D$ the values become $y / D=40, F r=1.8$ and $C_{0} / C_{\mathrm{m}}$ from Fig. 20 is less than 40 . Thus, if the interpretation given in $\S 7$ is valid, it is so only over a restricted range of possible design values.

89. Apart from this, caution must be used if outfalls are designed with low densimetric Froude numbers in the vicinity of 1.0 , because viscous influence may become significant and Abraham's results are valid only for turbulent jets. Perhaps more important may be the necessity to maintain reasonable velocities, not only to achieve self-cleansing conditions in the main pipe but also to inhibit marine growths around the discharge ports.

\section{Dr R. Silvester, University of Western Australia}

The Authors purport to compare a new series of sprinkler type devices for sewage dilution with those listed in previous literature. Those reported had been analysed and tested for ambient conditions and appeared to give a maximum increase over conventional ports of $100 \%$. The new devices were tested only in flowing streams which gave up to eleven times normal dilution. The comparisons are not valid because of the different conditions.

91. Reference was made to my initial paper on this subject, ${ }^{5}$ corrigenda to which were published later. ${ }^{10}$ The work by Patarapanich ${ }^{6}$ is also given in reference 11 .

92. It was stated that no allowance was made in the mixing tube cited for differences in density of driving and driven fluid. For the modest differentials between sewage and sea water the curves used ${ }^{12}$ would show negligible changes in the momentum exchange, but the buoyant effects entered the dilution calculations from the mixing tube exit. The influence of greater differences in density has been discussed by Silvester and Vongvisessomjai. ${ }^{13,14}$

93. If sewage outfalls are to be discussed generally the marine situation has to be considered as well as the stream outlet. The latter was the main concern of the Authors. In the ocean, wave forces, scouring and siltation must be taken into account, besides the diluting effects of waves. Storms can lift or rock structures on the sea bed, and this action can result in scour and subsidence. Such forces could detract from mixing tubes I used as much as it could from the Authors' vortex generators. It just leads to the conclusion that much more research is needed in this field, because effluent disposal is a continuous business that has great growth potential. Before new devices are devised the situation calls for another comprehensive survey of the status quo, similar to that conducted by Pearson in 1956. ${ }^{16}$

\section{Mr W. G. Gerald Snook, Parry, Froud and Snook}

The Authors state that the most efficient outfall in terms of maximum dilution at the water surface operates at a densimetric Froude number of unity. From a purely theoretical standpoint it is difficult to dispute this apparent mathematical fact. However, I would suggest that this statement holds good only when made relative to a comparison of single outlet types of discharge. 
95. For any given depth of water, effluent flow and ambient current velocity the multiport diffuser (with reducing main bore within the diffuser length) shows distinct advantages over the single outlet, providing not only higher initial dilution factors but also intrinsic practical operational advantages.

96. The Authors have drawn attention to the necessity for the Froude number to be greater than unity to avoid entrainment of sea water and for velocity in the main bore to be self-cleansing. Further practical considerations must always be taken into account at design stage to ensure not only economy of construction, but also successful operation with minimum maintenance. These practical considerations have an influence on the selection of the Froude number designed to prevail at various conditions of flow. Some of the considerations are as follows.

(a) For most of the time the bottom $5 \mathrm{ft}$ or so of water around British coasts contain a high degree of sea bed material in suspension, seaweed and marine life. This is particularly so as the water becomes more shallow.

(b) Most submarine outfalls do not operate on a continuous basis, but discharge intermittently.

(c) In addition to entrainment of sea water (and its contents) at Froude numbers below unity it is essential to consider entrainment when there is no discharge and also it is most important to consider the pumping effect of swell and waves due to the difference in pressure head between crest and trough. Under these conditions the suspended solids content of the sea water is obviously much greater.

(d) In coastal areas the gastronomic inclination of the holiday populus is inclined towards fried foods and consequently a much greater proportion of grease is contained within the sewage from such an area. This quickly forms on any surface in contact with stagnant or slow moving sewage.

(e) It can be seen from $(a)-(d)$ that it is essential that reasonably high velocities are designed into the system for all conditions of flow and particularly under conditions of low flow. This inevitably involves higher Froude numbers although ease of underwater maintenance designed into the system helps compensate this consideration.

( $f$ ) Relatively simple facilities should be provided for flushing out the discharge system should this be necessary as a result of regular (1-2 year intervals) underwater inspections.

(g) The discharge arrangements should not present an obstruction to trawling nets, anchor wires and so on.

97. With regard to the most ingenious device (model $\mathrm{K}$ ) the Authors have stated that its greatest value would be in comparatively shallow waters. Do the Authors intend that the device should be used in addition to or instead of multiport diffusers? Considering the example given of the application of such a device it is assumed that one single device would be incorporated on the end of an outfall of $0.38 \mathrm{~m}$ dia. From Figs $10(\mathrm{~K})$ and 11 it would seem that the device would be approximately $1.4 \mathrm{~m}$ high and $3.5 \mathrm{~m}$ in diameter. In view of the points in $\S 96(\mathrm{a})-(\mathrm{g})$ the device would have to be located some considerable height above sea bed level in order to avoid drawing in sea bed debris through the periphery, and the outfall itself would have to be taken above sea bed level in order to feed into the device in the manner shown. Although these requirements could be achieved in practice, they would prove expensive and cumbersome.

98. Considering the economics of providing the device situated as described so that it will resist nets, anchor wires and at the same time resist the drag and uplift forces of waves and currents, it would seem that the provision of a simple multiport diffuser might well show economic advantages as well as provide higher dilution factors.

99. Table 6 compares the various initial dilution factors (centre of the rising 
column) for different types of discharge arrangements. It is based on the example given in the Paper. I feel the design of any outfall system should be based on the ultimate capacity of that system and so I have included figures for the ultimate flow stated in the example of $0.3 \mathrm{~m}^{3} / \mathrm{s}$. There is also a column which gives the dilution factors which would be achieved in $8.75 \mathrm{~m}$ of water showing the theoretical reduction in the length of the outfall it would be possible to achieve with a multiport diffuser. I have used the same basis of design as the Authors did, but would suggest that perhaps there is an error in their anticipated dilution factors for flows of $0.06 \mathrm{~m}^{3} / \mathrm{s}$ for the open ended pipe. I also feel that their anticipated dilutions for $0.06 \mathrm{~m}^{3} / \mathrm{s}$ for the device might be a little low. Using the Authors' approach in reducing length of outfall it would be possible with the 12 ports of $0.100 \mathrm{~m}$ dia. to discharge into $7 \mathrm{~m}$ of water giving an initial dilution factor of 370 with a flow of $0.06 \mathrm{~m}^{3} / \mathrm{s}$ and reducing the length of the outfall to $884 \mathrm{~m}$.

100. Reference 1 advanced a means of calculating the additional dilution factor when discharge takes place into a moving ambient fluid. As calculation of final surface dilution factors depends to a great extent on the theories put forward in this Paper I would be interested to receive the Authors' comments on the regression analysis carried out to produce the equation

$$
\log (O / P \text { dilution ratio })=0.938 \log u_{\mathrm{a}} / u_{\mathrm{j}}+1 \cdot 107
$$

This analysis was based on the scatter from results of several different types of outfall including one outfall (G) with a multiport diffuser into deep water. If the regression

Table 6. Comparison of initial dilution factors

\begin{tabular}{|c|c|c|c|c|c|}
\hline \multirow{2}{*}{$\underset{m^{3} / s}{\text { Flow }}$} & \multicolumn{3}{|c|}{ Depth of water, $m$} & \multirow{2}{*}{$F$} & \multirow[t]{2}{*}{ Type of discharge } \\
\hline & 15 & $11 \cdot 5$ & $8 \cdot 75$ & & \\
\hline $\begin{array}{l}0.06 \\
0.12 \\
0.30\end{array}$ & $\begin{array}{c}250^{*} \\
100 \\
31\end{array}$ & $\begin{array}{c}170^{*} \\
55 \\
-\quad 22\end{array}$ & $\begin{array}{l}98 \\
41 \\
18\end{array}$ & $\begin{array}{l}1 \cdot 7 \\
3 \cdot 4 \\
8 \cdot 5\end{array}$ & $\begin{array}{l}\text { Open end } \\
0.38 \mathrm{~m} \text { dia. }\end{array}$ \\
\hline $\begin{array}{l}0.06 \\
0.12 \\
0.30\end{array}$ & $\begin{array}{c}370 \dagger \\
175 \\
60\end{array}$ & $\begin{array}{c}215 \dagger \\
100 \\
44\end{array}$ & $\begin{array}{r}170 \dagger \\
80 \dagger \\
35 \dagger\end{array}$ & $\begin{array}{l}\text { Depends } \\
\text { on } u_{\mathrm{a}}\end{array}$ & $\begin{array}{l}0.38 \mathrm{~m} \text { dia. } \\
\text { with device }\end{array}$ \\
\hline $\begin{array}{l}0.06 \\
0.12 \\
0.30\end{array}$ & $\begin{array}{r}392 \\
136 \\
46\end{array}$ & $\begin{array}{r}270 \\
102 \\
32\end{array}$ & $\begin{array}{r}175 \\
68 \\
23\end{array}$ & $\begin{array}{c}2 \cdot 034 \\
4.07 \\
10 \cdot 172\end{array}$ & $\begin{array}{l}2 \text { ports } \\
\text { of } 0.268 \mathrm{~m} \text { dia. }\end{array}$ \\
\hline $\begin{array}{l}0.06 \\
0.12 \\
0.30\end{array}$ & $\begin{array}{r}406 \\
185 \\
70\end{array}$ & $\begin{array}{r}295 \\
117 \\
50\end{array}$ & $\begin{array}{r}185 \\
78 \\
35\end{array}$ & $\begin{array}{l}5 \cdot 573 \\
10 \cdot 963 \\
27 \cdot 33\end{array}$ & $\begin{array}{l}5 \text { ports } \\
\text { of } 0.125 \mathrm{~m} \mathrm{dia} .\end{array}$ \\
\hline $\begin{array}{l}0.06 \\
0.12 \\
0.30\end{array}$ & $\begin{array}{r}855 \\
330 \\
90\end{array}$ & $\begin{array}{r}570 \\
210 \\
64\end{array}$ & $\begin{array}{r}370 \\
150 \\
48\end{array}$ & $\begin{array}{r}3.424 \\
6.859 \\
17.086\end{array}$ & $\begin{array}{l}8 \text { ports } \\
\text { of } 0.125 \mathrm{~m} \text { dia. }\end{array}$ \\
\hline $\begin{array}{l}0.06 \\
0.12 \\
0.30\end{array}$ & $\begin{array}{r}1100 \\
417 \\
126\end{array}$ & $\begin{array}{r}662 \\
288 \\
88\end{array}$ & $\begin{array}{r}497 \\
173 \\
63\end{array}$ & $\begin{array}{c}3.98 \\
8.01 \\
20.029\end{array}$ & $\begin{array}{l}12 \text { ports } \\
\text { of } 0.100 \mathrm{~m} \text { dia. }\end{array}$ \\
\hline Length & 1800 & 1380 & 1078 & & \\
\hline
\end{tabular}

- Suggested revised figures.

† Suggested too low. 
analysis had been carried out relative to the scatter of the results from outfall $G$ would the Authors comment on the possibility of the resulting equation being

$$
\log (O / P \text { dilution ratio })=1.297 \log u_{\mathrm{a}} / u_{\mathrm{j}}+1 \cdot 748
$$

If the approximate equation referred to would be applicable for multiport diffusers then the resulting increase in dilution factors as a result of the moving ambient fluid would be substantial.

101. Hansen and Schroder ${ }^{3}$ found that a simple $120^{\circ}$ wedge device placed in front of the discharge doubled the dilution factor. They also found by experiment that initial dilutions (without device) in the centre of the rising column were consistently greater than dilutions derived from theory ${ }^{2}$ by a factor of 1.45 . The Authors conclude that their own device also improves dilution by a factor of two. Can it be taken that both Hansen and Schroder's ${ }^{3}$ and the Authors' devices achieve the same result?

102. If the Authors' device were fitted to the diffuser ports of the in-line diffusers suggested in Table 6 they could be designed as an intrinsic feature of a domed net guard. In this case would the Authors expect an increase or decrease in the dilution factor achieved compared with the device of Hansen and Schroder?

103. In the past 18 years $I$ have sometimes been accused of designing submarine pipelines and diffusers which are too long. I still maintain that a minimum average initial dilution factor of 100 at ultimate flow should be aimed for irrespective of the length of the submarine pipeline which, in turn, should be governed by the assessment of subsequent dispersal characteristics of the locality related to the assessed $E$. Coli mortality rate to produce assessed $E$. Coli counts of not more than $10 / \mathrm{ml}$ for $80 \%$ of the time in $10 \mathrm{ft}$ of water at low water spring tides.

\section{Mr Agg and Dr White}

A densimetric Froude number of unity is the theoretical limit below which the pipe will not flow full of sewage. A practical limit for outfalls in the sea may well be, as Mr Osorio suggests, as high as three, particularly when multiple outlets are used. More information on observed discharge performance under prototype conditions would be valuable. The reference to better mixing being achieved at the highest ambient velocity relates to the percentage distribution of effluent in annular sections, as shown in Table 2, and compares with the values given in the footnote to Table 1 for complete mixing.

105. With regard to Mr Bruce's comments, the chart for zero ambient velocity is given in Fig. 21. This indicates contours for initial surface dilution which slope in the opposite direction to those given in Figs 1-3. This is a fundamental difference between the still and moving water cases within the range of conditions considered in the Paper, i.e. $1<F r<10$ and $u_{\mathrm{a}} / u_{\mathrm{j}}<2 \cdot 0$. An elaboration on this point is given in the context of Dr Sharp's remarks.

106. The philosophy behind the form of presentation for initial dilution data given in Figs 1-3 and 21 is that the diameter of the outlet is separated from most of the other variables and hence occurs in only one of the dimensionless parameters: $D / y$. Thus, for fixed values of the other variables $Q, y, u_{\mathrm{a}}, g, \rho_{0}$ and $\rho_{\mathrm{a}}$, the effect of changing the diameter of the outlet is readily obtainable. Thus Fig. 1, for example, shows that dilution increases with increasing $D / y$ and hence, for a fixed value of $y$, increasing $D$, within the range of $F r$ quoted. If the effect of a change in $y$ for a given $D$ is required the form of Figs $1-3$ and 21 is not very convenient and a set of charts based on Dr Sharp's equation (5) would be more appropriate. This is because the depth $y$ occurs in only one of the dimensionless groups in equation (5) whereas $y$ occurs in all groups in equation (4). In terms of the format given in Figs 1-3 and 21 a change in depth $y$ implies movement along both the ordinate and the abscissa and a significant change in $y$ would also necessitate moving from one chart to another because the ambient velocity parameter includes depth as one of the variables. When all these factors are 


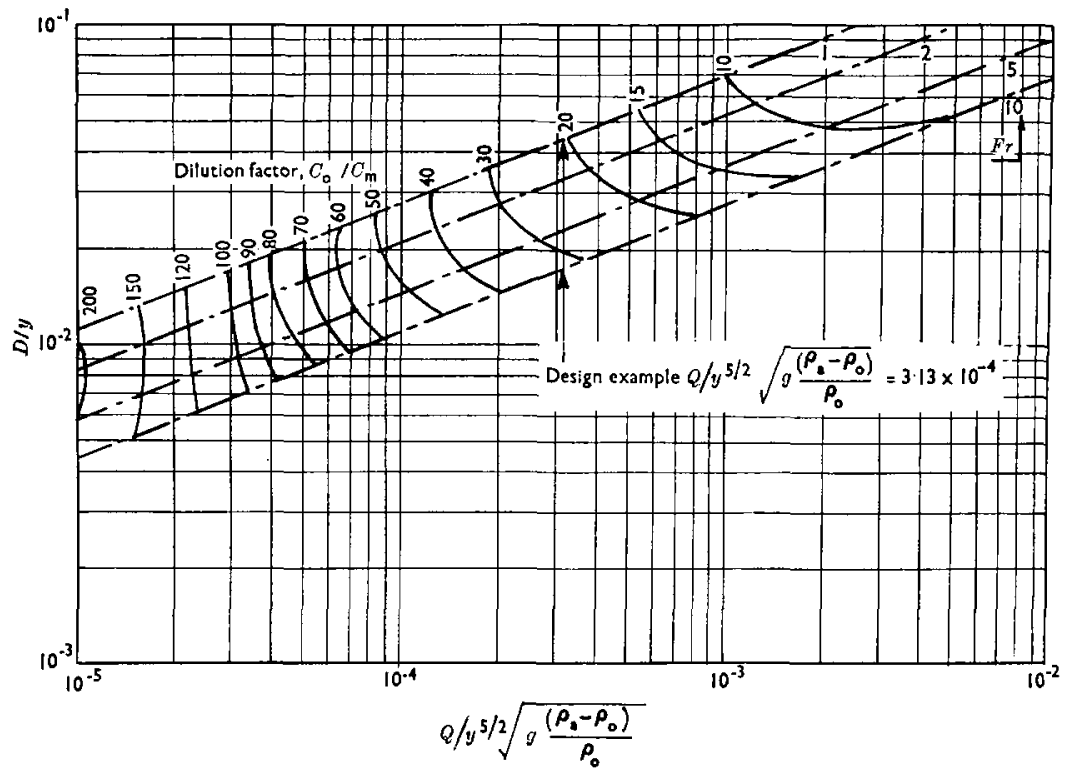

Fig. 21. Initial dilution data after Abraham ${ }^{2}$ (horizontal jet into still water); effluent discharged into still water, ambient conditions $u_{\mathrm{a}}=0$

taken into account the data presented in the Paper indicate, as would be expected, that dilution increases with depth and not the other way round as suggested by $\mathrm{Mr}$ Bruce.

107. In producing the design data given in Figs 1-3 we had to make use of the information available. Initial dilution in still water is well covered in the literature and reliable; similar data for horizontal, vertical and angled jets have been presented for example in references $2,3,7$ and 16-19. Initial dilution in moving water is less well documented but is discussed in references 1 and 20-22. Unfortunately there is little overlap in terms of the range of conditions investigated and where comparisons are possible the agreement is poor.

108. We sought to produce design data suitable for use in designing outfalls in UK waters, and a survey of existing outfalls suggested that horizontal outlets were the most common and that the emergent jet was normally in the range $1<F r<10$. Details have been given in reference 23. The data most appropriate to these needs are those of Agg and Wakeford ${ }^{1}$ which are based on field observations at existing UK outfalls. Their results indicate that, for practical purposes, initial dilutions in moving water can be obtained by multiplying the basic still water dilution (based on Abraham's data for horizontal jets) by a factor which increases with the ratio $u_{\mathrm{s}} / u_{\mathrm{f}}$. Thus the field experiments suggest that, at a given outfall operating at a particular flow rate, the initial surface dilution increases as the ambient current increases and the jet trajectory lengthens and deflects downstream.

109. On theoretical grounds the Agg and Wakeford approach imposes a constraint on the analysis which is not justifiable, i.e. they assume that

$$
\frac{C_{0}}{C_{\mathrm{m}}}=\phi^{*}\left(\frac{y}{D}, F r\right) \phi^{\prime \prime \prime \prime}\left(\frac{u_{\mathrm{a}}}{u_{\mathrm{s}}}\right) \text {. . . . . . . . }
$$


instead of the more general expression given in equation (3). However, the full functional relationships of equation (3) are not yet determined and at present it is necessary to use the simplified approach. The Hydraulics Research Station plan experiments on low Froude number horizontal jets in a cross flow, but in the absence of these data Figs 1-3 are based on the simplified relationships derived by Agg and Wakeford. ${ }^{1}$

110. Figure 17 indicates a significant lateral movement of the emergent jet and we deduce that this was probably associated with a relatively high value for the densimetric Froude number of the jet. Under these circumstances we would agree that there is a considerable difference in initial surface dilutions between horizontal and vertical jets. However, at low emergent Froude numbers, data suggest ${ }^{16}$ that initial surface dilutions obtained with horizontal jets are only about $10 \%$ higher than with vertical jets. This forms our basic justification for using the data in Figs 1-3 (horizontal outfalls) for tracking the jet to the surface even when the pre-dilution device produces a vertical jet. Indeed, it could be argued that model K (Fig. 11) produces a spiralling jet which would enhance dilution levels and more than compensate for the basic $10 \%$ deficiency. More research into this topic is required.

111. In reply to Mr Finch, we would emphasize that the design charts are constructed using dimensionless numbers so that the effect of density is taken into account provided the appropriate values are used in calculating the two density-dependent parameters. The model tests were carried out using typical density values for sewage and sea water as defined in $\$ 18$. The term 'effluent' was used because the hydraulic performance would be similar for liquids other than sewage but having the same density.

112. The particular problems associated with discharges to the Mediterranean Sea, mentioned by Mr Lovatt, are outside the scope of the Paper but are discussed in detail in reference 24.

113. We appreciate the practical problems mentioned by $\mathbf{M r}$ Ackers which are associated with relatively large pre-dilution devices. One advantage of model $\mathrm{K}$ over the other types of pre-dilution device tested is, in our opinion, that the conical shape would minimize the risk of fouling nets and anchors. Certainly, this device would be no more of a hazard than the commonly found swan-neck outlets. Although not a pleasant job, the removal of marine growths would be no more difficult than with a plain outlet. Access through the top of the device would be a possibility. Sedimentatlon within the device might occur from the ingress of sea bed material or from the deposition of gross solids from the effluent. To avoid the former problem it is suggested that the pre-dilution device should be raised marginally above sea bed level on a base or plinth. Deposition of gross solids is a problem with any type of outfall and the only real solution is screening and/or comminution at the source.

114. Most UK outfalls operate with a gravity feed, thus avoiding pumping costs. However, if pumping costs are considered acceptable, the mixing of sea water with the raw effluent as suggested by $\mathrm{Mr}$ Ackers is another practical way of achieving a degree of pre-dilution. It is not possible to predict the performance of pre-dilution devices when discharging this mixed effluent because the devices rely on the marked density difference between raw effluent and sea water to achieve pre-dilution. Thus data presented in the Paper are not applicable in this situation and Table 5 must be treated with caution.

115. The demand curve referred to by Mr Ackers has been presented elsewhere ${ }^{23}$ and is reproduced in Fig. 22. It is suggested, as a basis for discussion, that an outfall positioned close to the shore line would in general be required to produce an initial dilution higher than one further out to sea, and further offshore initial dilution would become unimportant. Superimposed on this general pattern would be some criteria for minimum tolerable dilution levels related to the formation of visible slicks. Slicks will occur with initial dilution levels below about 100 ; they will occur only infrequently with initial dilution levels in excess of about 400 , and in between these 


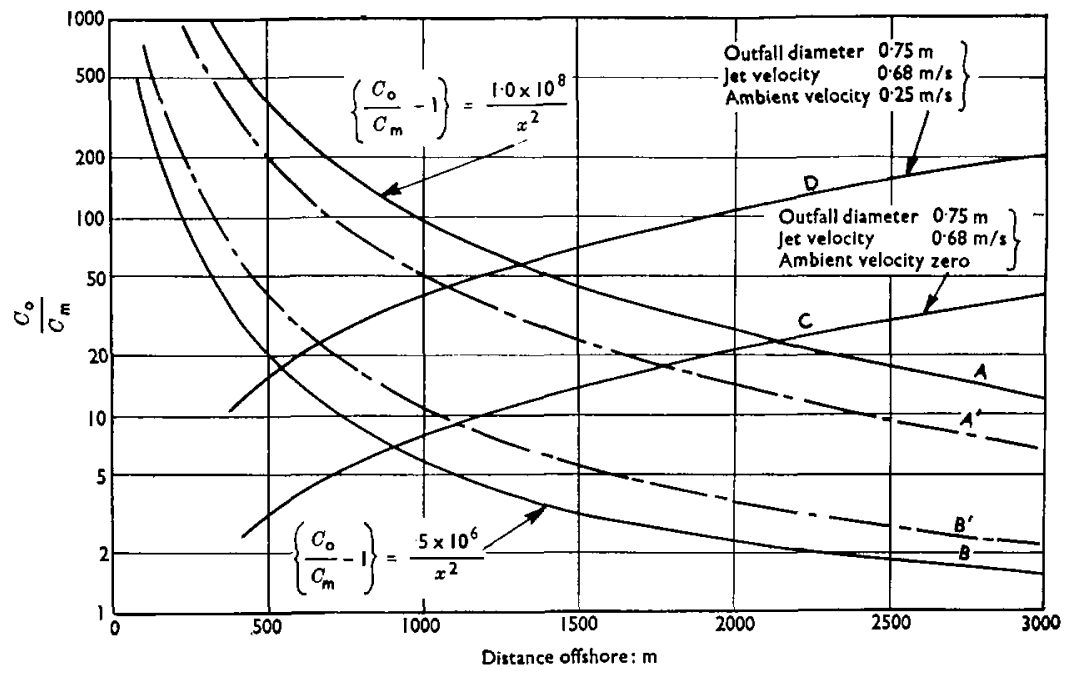

Fig. 22. Initial dilution plotted against distance offshore; assumed offshore slope 1 in 100

limits the grease content of the effluent will influence slick formation. ${ }^{25}$ There is some evidence from observations off the Dutch coast ${ }^{26}$ that subsequent vertical mixing of the sewage field with underlying sea water will not be restricted if the initial dilution factor exceeds 50 .

116. The design requirements in terms of initial dilution are not listed in any design code and hence hypothetical criteria are proposed for discussion. Curves of suitable shape are given by an equation of the form

$$
\frac{C_{0}}{C_{\mathrm{m}}}-1=\frac{\alpha}{x^{2}} \text {. . . . . . . . . . }
$$

where $C_{\mathrm{o}} / C_{\mathrm{m}}$ is the initial dilution ratio at the surface, $\alpha$ is a constant related to the requirements of individual sites and $x$ is the distance in metres of the outfall from the shore line.

117. Four curves are plotted in Fig. 22 for different values of $\alpha$. Curve $A$ ( $\alpha=$ $10^{8} \mathrm{~m}^{2}$ ) might be applicable to a site of high amenity value where a high degree of initial dilution is required; curve $B\left(\alpha=5 \times 10^{6} \mathrm{~m}^{2}\right)$ might be applicable to a remote site where initial dilution is relatively unimportant. The intermediate curves $\mathbf{A}^{\prime}$ and $\mathbf{B}^{\prime}$ are for coefficients $\alpha$ of $5 \times 10^{7}$ and $10^{7} \mathrm{~m}^{2}$ respectively.

118. These four curves in Fig. 22 represent design requirements in the form of initial dilution levels at various distances from the shore line for different degrees of sensitivity related to local situations. It is interesting to compare the initial dilution levels which the designer can, in practice, achieve. There is no unique answer because the engineer can vary some of the relevant parameters in his design procedure. Two principal factors which influence initial dilution are the depth of the outfall beneath the surface and the ambient current velocity; these can be altered only by changing the position rather than the form of the outfall.

119. As examples of the initial dilutions which can be achieved using a simple horizontal pipe in still and moving water, two attainable curves are plotted in Fig. 22 (curves C and D) for a pipe diameter of $0.75 \mathrm{~m}$, an effluent flow of $0.3 \mathrm{~m}^{3} / \mathrm{s}$, and an 
offshore sea bed slope $S_{0}$ of 1 in 100-all typical UK figures. The densimetric Froude number of the effluent discharge is thus 1.55. Curve $\mathrm{C}$ is for still (slack) water situations and curve $D$ assumes an ambient current of $0.25 \mathrm{~m} / \mathrm{s}$-again a typical UK figure.

120. Clearly, the design length for the outfall is where the required and attainable dilution curves coincide. At the difficult site-where high initial dilutions are required and the ambient velocities are low-the two curves will cross furthest from the shore line. Conversely, at sites with no requirement for high initial dilutions and where ambient currents are strong, the intersection will be much closer to the shore line. This approach is suggested as a logical method of determining outfall length. There is obviously pressure on the engineer, particularly when faced with a difficult site, to find the most economic solution to the problem and in the context of this design method the problem resolves into considerations of the ways, means and costs of modifying the curves for the attainable initial dilutions so that the stipulated requirements are met.

121. Hot water was used in the experimental work at the Hydraulics Research Station and Mr Ackers is right to query the possible effects of heat losses through the walls of the devices. However, data presented in Table 2 suggest that heat losses were not significant, and we believe that the methods adopted were adequate for the purposes of the exercise. Tests at a larger scale and with an insulated device would be required to prove this point.

122. Professor Francis suggests that, because of the non-scale effects of boundary layers, prototype pre-dilution devices may be less efficient than their model counterparts. We are well aware of scale effects and have noted the phenomenon he described in tests on rotary aeration devices. However, the analogy between model $\mathrm{J}$ and a swirl atomizer seems to be a very tenuous one. The pre-dilution devices mix two fluids of similar density at relatively low velocities. The opposite is true in the case of the swirl atomizer.

123. The model devices were considerably larger than Professor Francis imagines and the model $\mathbf{K}$ was tested at two different scales. The external diameter of the smaller model was $180 \mathrm{~mm}$ and that of the larger model was $240 \mathrm{~mm}$. Table 2 gives the results for these two models when operating with Froudian similarity. These may be summarized as shown in Table 7. It is doubtful whether the small differences in performance are significant.

124. For the sake of simplicity the design example has been related to a single outlet. A multiple port outfall can be regarded as producing a series of individual jets each of which can be treated separately. An additional parameter involved is the separation between the ports which, for a given depth of water, determines the interference between adjacent jets. In reply to Messrs Ashworth and Lindsay reference 23 discusses the relative benefits of multiple ports and pre-dilution devices. It also deals with hydraulic performance and physical dilution at the point of outfall. The disappearance of coliforms in the sea should be associated with calculations of subsequent dispersion between the outfall and some point of interest, such as the beach. Com-

\section{Table 7}

\begin{tabular}{|c|c|c|c|c|c|}
\hline \multirow{2}{*}{$\begin{array}{c}\text { Prototype } \\
\text { diameter, } \\
m\end{array}$} & \multirow{2}{*}{$\begin{array}{c}\text { Model } \\
\text { diameter, } \\
m m\end{array}$} & \multirow{2}{*}{$\begin{array}{c}\text { Model } \\
\text { scale }\end{array}$} & \multicolumn{3}{|c|}{ Average dilution factors for prototype velocities } \\
\hline & & & $u_{\mathrm{a}}=0.05 \mathrm{~m} / \mathrm{s}$ & $u_{\mathrm{a}}=0.26 \mathrm{~m} / \mathrm{s}$ & $u_{\mathrm{a}}=0.51 \mathrm{~m} / \mathrm{s}$ \\
\hline $\begin{array}{l}0.48 \\
0.48\end{array}$ & $\begin{array}{l}180 \\
240\end{array}$ & $\begin{array}{l}1: 26 \cdot 7 \\
1: 20.0\end{array}$ & $\begin{array}{l}6 \cdot 3 \\
5 \cdot 8\end{array}$ & $\begin{array}{l}6 \cdot 4 \\
5 \cdot 4\end{array}$ & $\begin{array}{l}4 \cdot 0 \\
4 \cdot 4\end{array}$ \\
\hline
\end{tabular}


parative data on coliforms and physical dilution factors have been reported in reference 1.

125. Mr Calvert raises an important point which is frequently overlooked. Biological treatment is designed to produce an effluent meeting requirements of biochemical oxygen demand and suspended solids for discharge to inland rivers. However, the removal of coliform bacteria is limited to a reduction from the order of $10^{9} / 1$ to $10^{7} / 1$ so that a fully treated effluent contains substantial numbers of bacteria. Dissolved oxygen is unlikely to be a limiting factor in the open sea and natural turbidity due to material suspended by wave action is frequently greater in coastal waters than that caused by sewage.

126. Mr Oakley has asked for our definition of 'ambient velocity'. The measurements of ambient velocity in the experiments reported by Agg and Wakeford ${ }^{1}$ were made at a depth of $1.5 \mathrm{~m}$. In the present experiments the ambient velocity relates to the average flow of water over the cross-section of the plume.

127. Dr Sharp gives alternative ways in which dilution data for the moving water case might be presented. Equations (4)-(6) are all valid and each would have advantages when considering the effects of the different basic parameters.

128. Our charts are most useful to the designer who makes the choice of outlet diameter his final decision. We have assumed that the rate of discharge of effluent $Q$ is known and that the site for the outfall has been finalized, i.e. $y$ and $u_{\mathrm{a}}$ are known. Under these circumstances the optimum diameter for the outlet can readily be obtained from Figs 1-3 (or others in the series). To illustrate this it is useful to consider the example in Table 8 in which the densimetric Froude number is in the range $1<F r$ $<10$.

129. The discharge parameter $Q /\left\{y^{5 / 2} \sqrt{ }\left[\left(\rho_{\mathrm{a}}-\rho_{0}\right) / \rho_{0}\right]\right\}$ is $3 \cdot 13 \times 10^{-4}$. The ambient current parameter $u_{\mathrm{a}} /\left\{g\left[\left(\rho_{\mathrm{a}}-\rho_{0}\right) / \rho_{0}\right] y\right\}$ is zero when $u_{\mathrm{a}}=0$ and 0.15 when $u_{\mathrm{a}}=0.24 \mathrm{~m} / \mathrm{s}$. Hence Figs 1 and 21 apply to the two extremes of the ambient current range and the relationships between $C_{0} / C_{\mathrm{m}}$ and $D / y$ can be read directly from the charts. Having assumed a depth $y=10 \mathrm{~m}$, the relationships between diameter $D$ and initial dilution $C_{0} / C_{\mathrm{m}}$ are obtained for the still and moving water cases.

130. The results for the example chosen are plotted in Fig. 23, but before comparing the still and moving water cases it is necessary to modify either the Agg and Wakeford ${ }^{1}$ or the Abraham $^{2}$ initial dilution values to make them comparable. Abraham's theoretical curves predict initial dilution based on concentrations along the centre line of the plume and Agg and Wakeford reported initial dilutions based on average concentrations across the plume. The difference is probably a factor of about 1.7, with the Agg and Wakeford results appearing more optimistic in terms of initial dilution.

131. Curve A on Fig. 23 is for the still water case based on Abraham's theoretical curves relating initial dilutions in terms of concentrations along the centre line of the plume. Curve B is for the moving water case, after Agg and Wakeford, ${ }^{1}$ based on average concentrations across the plume. Curve $\mathbf{C}$ is a revised version of curve $B$ in which the $C_{0} / C_{\mathrm{m}}$ values of curve $\mathrm{B}$ have been divided by the factor $1 \cdot 7$. Curves $\mathrm{A}$

\section{Table 8}

Effluent fiow

Depth of outfall

Acceleration due to gravity

Density difference ratio

Range of ambient currents

$0.05 \mathrm{~m}^{3} / \mathrm{s}$
$10 \mathrm{~m}$
$9.81 \mathrm{~m} / \mathrm{s}^{2}$
0.026
$0<u_{\mathrm{a}}<0.24 \mathrm{~m} / \mathrm{s}\left(\simeq \frac{1}{2} \mathrm{knot}\right)$




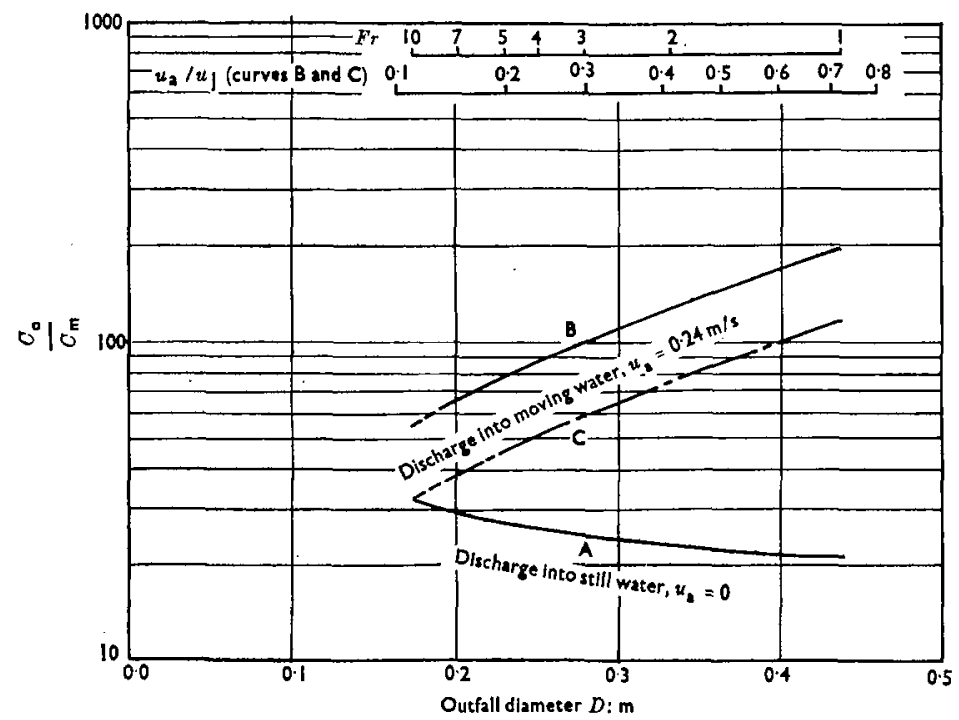

Fig. 23. Design example : initial dilution factors in terms of outfall diameter

and $\mathrm{C}$ are thus comparable. The scale at the top of Fig. 23 indicates how Fr varies with $D$ and the variation of the ratio $u_{\mathrm{a}} / u_{\mathrm{j}}$ with $D$ for curves $\mathrm{B}$ and $\mathrm{C}$ is also shown.

132. Conclusions to be drawn from Fig. 23 are that, within the working range of densimetric Froude numbers

(a) in still water there is a marginal advantage in terms of initial dilution levels in choosing the smallest practical diameter for the outfall and designing it to run at a densimetric Froude number of around 10; head losses may, of course, be unacceptable

(b) in an ambient current initial dilutions are significantly higher than the equivalent still water values; further, the initial dilutions obtained in moving water increase dramatically with increasing outfall diameter, largely because of the effect of the $u_{\mathrm{a}} / u_{\mathrm{j}}$ ratio.

Thus it appears that an ambient current should certainly be taken into account when estimating initial dilution levels and that, where an ambient current exists, the designer should increase the outfall diameter to the practical limit and operate at low densimetric Froude numbers, say in the range $1<F r<3$.

133. In $\$ \$ 87$ and $88 \mathrm{Dr}$ Sharp points out that Abraham's data for the still water case indicate that initial dilutions fall with increasing diameter, all other variables being constant. We agree, and the example quoted here confirms this trend. However, Figs 1-3 are for the moving water case where this trend is reversed. This is because the field experiments of Agg and Wakeford ${ }^{1}$ indicate that in moving water the equivalent still water dilutions must be multiplied by a factor which increases with $u_{\mathrm{a}} u_{\mathrm{k}}$. Their recommended expression takes the form

$$
\left(\frac{C_{0}}{C_{\mathrm{m}}}\right)_{\text {movine water }}=\left(\frac{C_{0}}{C_{\mathrm{m}}}\right)_{\text {at1ll water }} \times\left\{0.938 \log \frac{u_{\mathrm{a}}}{u_{\mathrm{j}}}+1.107\right\} .
$$

At a given site the designer has no control over the value of $u_{\mathrm{a}}$ but he can, for a given flow $Q$, reduce the value of $u_{j}$ by increasing the outlet diameter. It is this reduction 


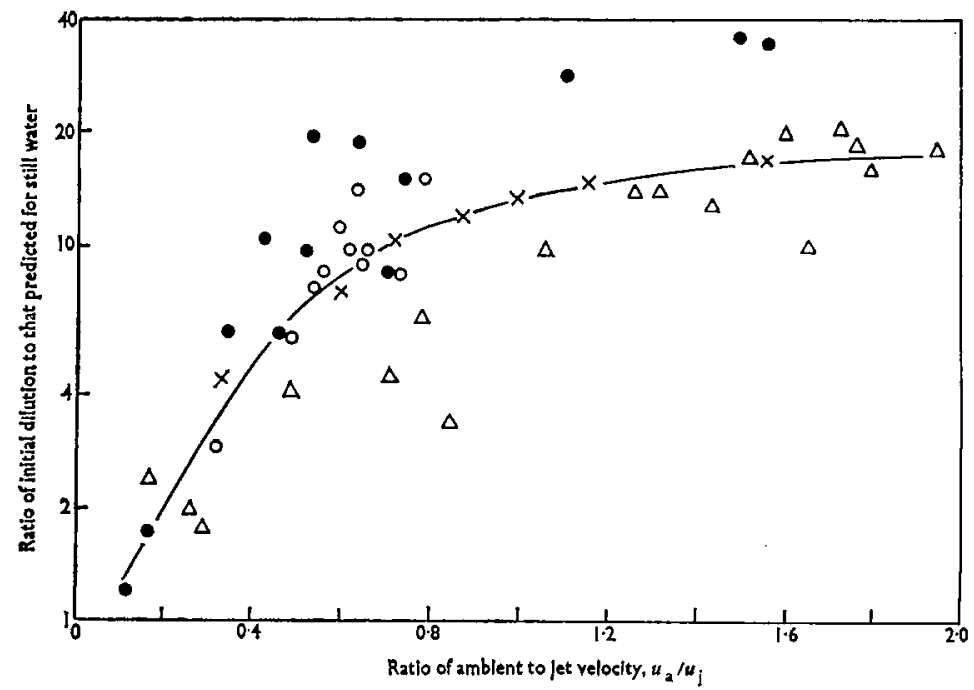

Fig. 24. Increase in initial dilution observed by Agg and Wakeford ${ }^{1}$ over that predicted by Abraham ${ }^{2}$ for still water

in $u_{1}$ which enhances initial dilution in moving water and reverses the relationship between diameter and initial dilution.

134. We appreciate the difficulties in operating at very low densimetric Froude numbers and for practical purposes would accept a limit $F r \nless 1.5$.

135. We welcome Dr Silvester's contribution particularly because of the additional references to work on mixing tubes which he gives. Comparisons between the jet pump type of diffuser and the conical vortex mixer which we developed are difficult to make. The mechanism by which two types of device achieve pre-dilution is different. The jet pump requires high velocities to achieve mixing and would probably be associated with pumped outlets whereas model $\mathrm{K}$ is a low velocity device more appropriate to gravity feed.

136. We experimented with a moving ambient fluid because tidal currents around the UK are strong enough to influence the performance of outfalls and designers wish to take these effects into account. Indeed, some of the devices relied on the ambient current to achieve mixing of the effluent before release and would be of little value in a stagnant fluid.

137. Mr Snook discusses practical difficulties of outfall operation and maintenance, and construction of different devices. The use of model $\mathbf{K}$ on individual ports of a multiple port outfall has since been considered in reference 23. Calculating the initial dilution factors from first principles for an effluent flow of $0.06 \mathrm{~m}^{3} / \mathrm{s}$ gives values in line with Mr Snook's suggestions; these compare with values interpolated between charts of 290 and 125.

138. The data in Figs 8 and 9 of reference 1 may be compared with those in Fig. 24. Here grouped means of dilution ratios from individual experiments have been plotted against the velocity ratio using a linear scale for the abscissa. This presentation $^{27}$ better illustrates the agreement with Abraham's predictions when the ambient velocity tends to zero.

139. It does not seem reasonable to propose an equation for general application to 
diffuser design based on observations at only one outfall. The variability in the field data is too great to allow individual experiments to be selected independent of the others. However, the full set covers a range of parameters shown in Fig. 11 of reference 1.

140. The device suggested by Hansen and Schroder ${ }^{3}$ was studied in still water so that the results are not directly comparable with the present work in moving water.

\section{References}

8. Ayoub G. M. Dispersion of buoyant jets in a flowing ambient fluid. PhD thesis, University of London, 1971.

9. Ayoub G. M. Test results on buoyant jets injected horizontally in a cross flowing stream. Wat., Air Soil Pollution, 1973, 2, 409-426.

10. Silvester R. Jet mixers in sewage outfalls. J. Instn Engrs Aust., 1967, $39,95$.

11. Silvester R. and Patarapanich M. Use of mixing tubes on marine outfalls. Proc. 13th Conf. Coastal Engng, 1972, 4, 2171-2186.

12. Silvester R. and Mueller N. H. G. Design data for the liquid jet pump. J. Hydraul. Res., 1968, 6, 129-162.

13. Silvester R. and Vongvisessomjai S. Characteristics of the jet-pump with liquids of different density. Proc. 3rd World Dredging Conf., 1970, 293-315.

14. Silvester R. and Vongvisessomjai S. The jet pump using liquids of different density. Proceedings of symposium on jet pumps and ejectors, 1972, 171-181.

15. Pearson E. A. Investigation of the efficacy of submarine outfall disposal of sewage and sludge. California Water Pollution Control Board, 1956, Publn. 14.

16. DePARTMENT OF THE ENVIRONMENT. Hydraulics Research 1972. HMSO, London, 1973, 21.

17. FAN L. N. and Brooks N. H. Numerical solutions of turbulent buoyant jet problems. W. M. Keck Laboratory of Hydraulics and Water Resources, California Institute of Technology, 1969, Report KH-R-18.

18. Frankel R. J. and Cumming J. D. Turbulent mixing phenomena of ocean outfalls. J. Sanit. Engng Div. Am. Soc. Civ. Engrs, 1965, 91, SA2, 33.

19. HAYASH T. and ITO M. Initial dilution of effluent discharging into stagnant sea water. International symposium on the discharge of sewage from sea outfalls, London, 1974, Paper 26.

20. Pearce A. F. Dispersal of effluents at submarine outfalls. Council of Scientific and Industrial Research, Pretoria, 1968, Report MEG 692.

21. FAN L. N. Turbulent buoyant jets into stratified or flowing ambient fuids. California Institute of Technology, Report KH-R-15.

22. Melbourne W. H. Wind tunnel modelling of buoyant chimney plumes. Proceedings of the third conference on hydraulics and fluid mechanics. Institution of Engineers, Australia, 1968.

23. WhIte W, R. and AGG A. R. Outlet design. International symposium on the discharge of sewage from sea outfalls, London, 1974, Paper 27.

24. Second international congress on marine pollution and marine waste disposal, San Remo, 1973.

25. Newton J. R. Factors affecting slick formation at marine sewage outfalls. Conference on pollution criteria for estuaries. University of Southampton, 1973, Paper 12.

26. Abraham G. and Brolsma A. A. Diffusers for disposal of sewage in shallow tidal water. International Association for Hydraulic Research Congress, Leningrad, 1965, 2, 1.

27. Department of THE ENVIRONMENT. Water pollution research 1971. HMSO, London, 1972. 